\title{
Effect of Nickel pre-plating on the Plating of Zn-Ni Alloy Coating on Stainless Steel Substrate
}

\author{
X. D. LIU ${ }^{1}$; Y. ZHOU ${ }^{1}$; C. Y. NIE ${ }^{* 1}$; J. LIU²; C.Y. XIAO ${ }^{2}$ \\ ${ }^{1}$ Faculty of Materials and Energy, Southwest University, Chongqing 400715, China \\ ${ }^{2}$ Chongqing LIDAO S\&T Co., Ltd, Chongqing 402263, China \\ *Corresponding author: niecy@swu.edu.cn
}

\begin{abstract}
Keywords: Nickel pre-plating, electroplating Zn-Ni alloy, Membrane binding strength, corrosion resistance
\end{abstract}

\begin{abstract}
Nickel pre-plating on stainless steel parts, electroplating Zn-Ni alloy layer on the basis of pre-plating layer. In order to improve the bonding strength between the coating and substrate by the introduction of nickel to form a good bonding with the iron matrix. To explore the influence of nickel pre-plating process on the film base bonding strength of $\mathrm{Zn}-\mathrm{Ni} / 304$ stainless steel. The morphologies, Rockwell hardness indentation and phase structure of the $\mathrm{Zn}-\mathrm{Ni}$ alloy plating were characterized with Scanning Electron Microscopy (SEM), Metallographic microscope observation, $\mathrm{X}$-ray diffraction (XRD). Corrosion resistance of the Zn-Ni alloy plating was evaluated by electrochemical polarization tests. Results show that after nickel pre-plating adhesion of the coating and stainless steel substrate improved significantly, and the corrosion resistance also improved relative to the direct plating $\mathrm{Zn}-\mathrm{Ni}$ alloy coating.
\end{abstract}

\section{Introduction}

304 austenitic stainless steel is widely employed in home appliances, auto parts, food industry because of its good corrosion resistance, heat resistance, low temperature strength and mechanical characteristics ${ }^{[1]}$.But in corrosive environment such as chlorine, under the condition of high temperature, it can't have good protection effect and easy to corrode. Zn-Ni alloy plating, as a new protective coating has been applied widely in the automobile industry at home and abroad, because of its excellent resistance to corrosion, low hydrogen embrittlement, excellent weldability and mechanical properties ${ }^{[2]}$.

Zn-Ni alloy coating deposited on stainless steel effective corrosion protection of stainless steel parts, in some cases, but due to the stainless steel has a high chemical stability, easily forming a passivation layer on the surface ${ }^{[3]}$. When the electroplating of metal ion to the stainless steel surface movement, their adhesion is not strong and easy to fall off. This is because of the conductivity of surface oxides are not very good ${ }^{[4]}$, and the oxide film capacitor formed in solution and metal oxide interface forming a capacitor and electric double layer capacitor, exclusion of electroplated metal ${ }^{[5]}$.

This study using the nickel pre-plating ${ }^{[6]}$ to form a layer of transition layer, so as to improve the Zn-Ni alloy and stainless steel film substrate adhesion. By examining the coating indentation, electro-chemical corrosion resistance to explore the effect of nickel pre-plating on the plating of Zn-Ni alloy coating on stainless steel substrate, thus valuable experimental data was provided for the production and reference.

\section{Experimental Procedure}

This research with the substrate material is 304 stainless steel mirror polishing, specifications for $30 \mathrm{~mm} \times 20 \mathrm{~mm} \times 1 \mathrm{~mm}$, on a substrate of electrodeposited nickel coating thickness is about $2 \mu \mathrm{m}$, Zn-Ni alloy plating thickness between $5 \mu \mathrm{m}-6 \mu \mathrm{m}$. Nickel pre-plating process for stainless steel: ultrasonic degreasing $\rightarrow$ washing $\rightarrow$ activation $\rightarrow$ washing $\rightarrow$ nickel pre-plating on stainless steel. Cleaning the sample of nickel pre-plating, and then electroplating $\mathrm{Zn}-\mathrm{Ni}$ alloy coating. The specific 
process is as follows: washing $\rightarrow$ Zn-Ni alloy electroplating on the nickel pre-plating layer $\rightarrow$ washing $\rightarrow$ passivation $\rightarrow$ washing $\rightarrow$ drying $\rightarrow$ inspection.

The crystal structure of Zn-Ni alloy plating coating was analyzed by X-ray diffractometer with a $\mathrm{Cu}$ radiation target $(\lambda=1.56 \mathrm{~A})$. The $\mathrm{X}$-ray diffraction using the excitation voltage of $40 \mathrm{kV}$ and $50 \mathrm{~mA}$ of current. Surface morphology of Zn-Ni alloy plating and Rockwell indentation morphology were characterized by scanning electron microscopy (SEM). Wuhan Kesite CS350 electrochemical workstation was choosed to test the electrochemical performance of Zn-Ni alloy plating coating and Zn-Ni alloy coating after nickel plating. Electrochemical tests using three-electrode system, reference electrodes are saturated calomel electrode, and auxiliary electrodes are platinum. The preparation of electrodeposited Zn-Ni alloy coating and plating electrodeposited of Zn-Ni alloy after coating as working electrode. Mass fraction of $5 \% \mathrm{NaCl}$ solution as dielectric of electrochemical test, working electrode surface area for $1 \mathrm{~cm}^{2}$. First measure the open circuit potential of the working electrode, then measure the Zeta potential of the working electrode, and electro-chemical corrosion morphology were observed.

\section{Results and discussion}

\section{The XRD phase of Zn-Ni alloy coating}

By x-ray diffraction, respectively of electrodeposited Zn-Ni alloy plating and electrodeposited Zn-Ni alloy after nickel pre-plating coating phase detection and analysis. Two samples of XRD patterns as shown in Fig.1.
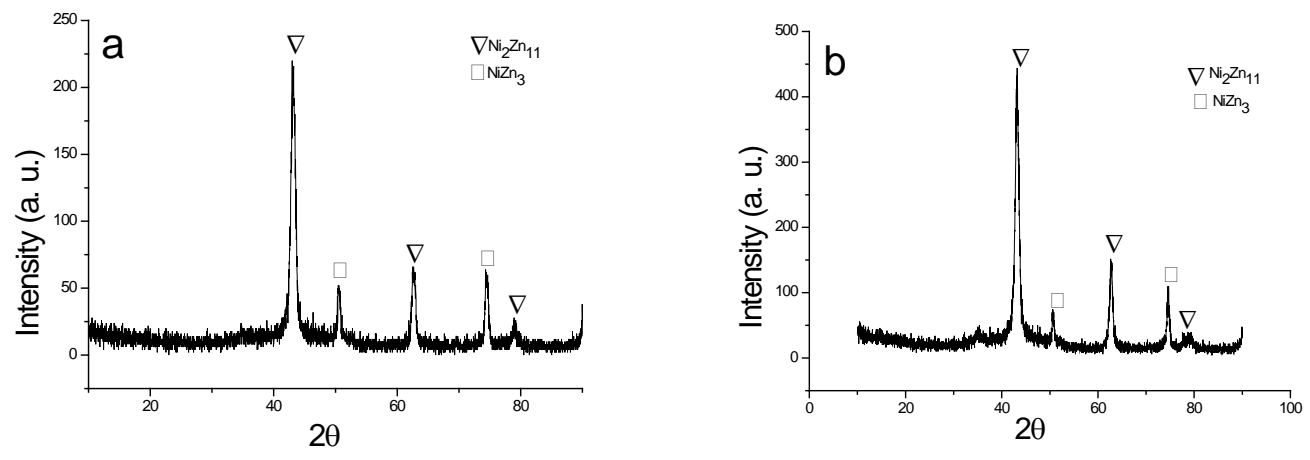

Figure 1 The XRD spectra of the two samples of Zn-Ni alloy coating: (a) direct plating, (b) after the nickel pre-plating.

You can see from Fig.1, Zn-Ni alloys (330) face a maximum intensity characteristic peak ( $\gamma$-phase) are appearing in $2 \theta=43.22^{\circ}$ and weaker diffraction peak appearing at $62.5^{\circ}, 79^{\circ}$. The figure with the standard $\mathrm{Zn}-\mathrm{Ni}$ alloy XRD maps are basically the same. Its molecular formula is $\mathrm{Ni}_{2} \mathrm{Zn}_{11}$, which is stable in the condition of room temperature to $650^{\circ}{ }^{[7]}$, and do not form a micro-cell corrosion, which is beneficial to improve the corrosion resistance of the coating. The composition of the surface of the Fig.1a coating is basically consistent with that of the Fig.1b coating, which indicates that the nickel pre-plating has no effect on the surface phase structure of the $\mathrm{Zn}-\mathrm{Ni}$ alloy coating.

\section{Micro-structure analysis of Zn-Ni alloy plating}

Fig.2 is a scanning electron microscope magnified 3000 times of electrodeposited Zn-Ni alloy coating and electrodeposited Zn-Ni alloy coating after nickel pre-plating. It can be seen from the two pictures, the surface is relatively smooth, both at the same time distribution of the micro cracks. Fig.2a shows that the size of the micro cracks in the surface plate for 10 to 15 microns. From Fig.2b, the surface micro cracks in the surface plate for 5-10 microns, the size of the micro cracks distribution is more uniform, smooth and dense. Test results show that nickel pre-plating makes Zn-Ni alloy coating deposition more uniform and organization more refined. 

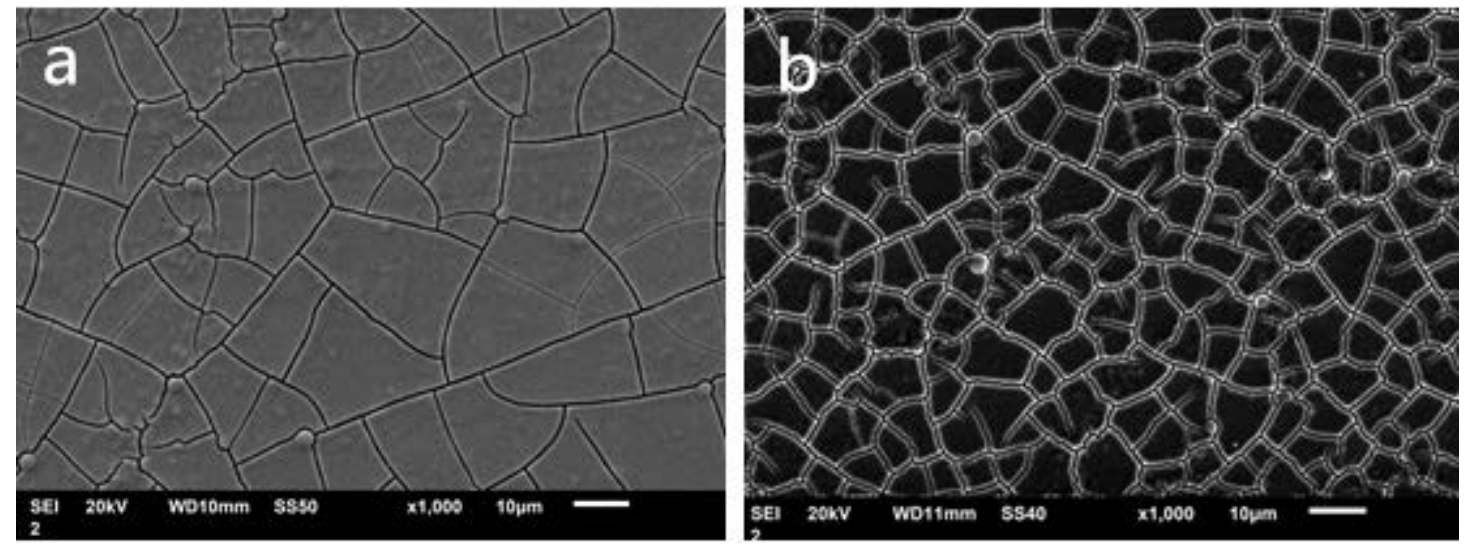

Figure 2 The SEM image of Zn-Ni alloy: (a) direct Zn-Ni alloy electroplating coating, (b) Plating Zn-Ni alloy coating after nickel pre-plating.

\section{Analysis of indentation shape of Zn-Ni alloy plating}

Fig.3 shows that direct electrodeposition of $\mathrm{Zn}-\mathrm{Ni}$ alloy plating and after nickel pre-plating electrodeposition of $\mathrm{Zn}-\mathrm{Ni}$ alloy plating indentation topography. Fig.3a shows direct electrodeposition of Zn-Ni alloy coating, the edge of the indentation is massive spalling phenomena. Fig.3c is Fig.3a further enlarge. Indentation block on the edge of spalling phenomenon is more obvious in the Fig.3c. You can see from Fig.3, the indentation of the perimeter of the coating was broken under the action of stress, and the crack extension. From Fig.3b can see after pre-nickel plating electrodeposition of $\mathrm{Zn}-\mathrm{Ni}$ alloy plating flake indentation edge does not appear, from its further amplification can be seen in the Fig.3d, under the effect of shear stress, the ridges appear on the edge of the indentation, but still together as one.

Different phenomenon is explained by the following two aspects. On the one hand, the chemical stability of stainless steel is higher, easy to form a layer of surface passivation layer. When the electroplating of metal ion to the stainless steel surface movement, because of the poor surface oxide conductivity, the exclusion of plating metals, easily lead to adhesion is not strong. Nickel layer, on the other hand, can be combined with iron substrate to form a good material, to a certain extent improve the cohesive force of the coating, ${ }^{[8]}$, nickel plating and stainless steel of the iron atoms form a dense, uniform nickel alloy plating ${ }^{[9]}$, effectively prevent the stainless steel surface passivation again, to ensure the coating adhesion strength of hard coatings. 

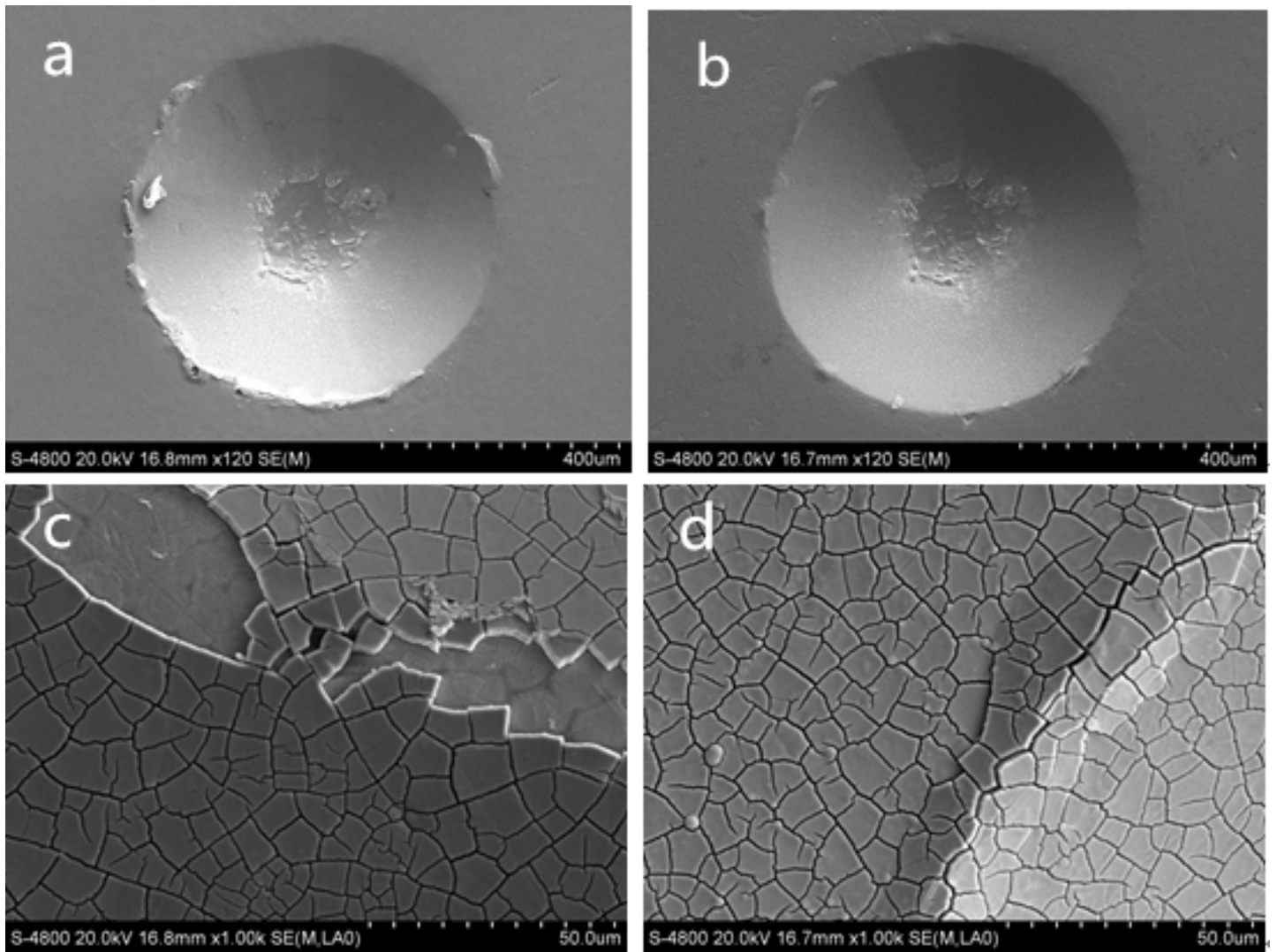

Figure 3 The indentation SEM of Zn-Ni alloy coating: (a) (c) direct Zn-Ni alloy plating coating, (b) (d) Plating Zn-Ni alloy coating after nickel pre-plating.

\section{Analysis of electrochemical corrosion properties of $\mathrm{Zn}-\mathrm{Ni}$ alloy coating}

Fig.4 for direct electroplating Zn-Ni alloy coating and after nickel pre-plating electroplating Zn-Ni alloy coating in $5 \% \mathrm{NaCl}$ electrolyte solution of polarization curve. Polarization curve formed by anodic polarization curve and cathodic polarization curve. By Fig.4a combined with the data in table 1. In 5\% $\mathrm{NaCl}$ solution, after nickel pre-plating electrodeposition of $\mathrm{Zn}-\mathrm{Ni}$ alloy coating from the corrosion potential is higher than direct electroplating $\mathrm{Zn}-\mathrm{Ni}$ alloy plating, the corrosion potential of the former relative to the latter was $127 \mathrm{mv}$, and the matrix form of micro battery electromotive force is small, its smaller corrosion driving force ${ }^{[10]}$.

Table 1 The corrosion and corrosion current density results of two sample in a solution of electrolyte solution $5 \% \mathrm{NaCl}$.

\begin{tabular}{|l|l|l|l|l|}
\hline $\begin{array}{l}\text { Electrolyte } \\
\text { Solutions }\end{array}$ & Samples & $\mathrm{I}_{\text {corr }} /(\mathrm{mA})$ & $\mathrm{E}_{\text {corr }} / \mathrm{V}$ & $\mathrm{J}_{\text {corr }} /\left(\mathrm{mA} / \mathrm{cm}^{2}\right)$ \\
\hline $5 \% \mathrm{NaCl}$ & $\begin{array}{l}\text { Plating Zn-Ni alloy } \\
\text { coating after nickel } \\
\text { pre-plating }\end{array}$ & $2.538 \times 10^{-6}$ & -1.105 & $2.538 \times 10^{-6}$ \\
\cline { 2 - 5 } & $\begin{array}{l}\text { Direct plating Zn-Ni alloy } \\
\text { coating }\end{array}$ & $3.127 \times 10^{-6}$ & -1.232 & $3.127 \times 10-^{6}$ \\
\hline
\end{tabular}

Due to the preparation of Zn-Ni alloy coating belongs to $\gamma$ crystal type, so the corrosion current density is small and little difference. But experiments show that corrosion resistance ability of electroplating Zn-Ni alloy plating coating after nickel pre-plating is better than direct electroplating $\mathrm{Zn}-\mathrm{Ni}$ alloy coating, and the corrosion current density of the former is 0.812 times of that for the latter. The corrosion current density and corrosion rate proportional relations ${ }^{[11]}$, the smaller the corrosion current density, the smaller the corrosion rate. The corrosion current density of electroplating Zn-Ni alloy plating coating after nickel pre-plating is lower than direct electroplating 
Zn-Ni alloy coating. Zn-Ni alloy coating fall off into pieces the corrosion phenomenon is shown in Fig.5a. However, the coating of Fig.5b is a lot of corrosion by corrosion marks, eroded even shrinkage, but still not fall off. Investigate its reason, because of the nickel pre-plating make the $\mathrm{Zn}-\mathrm{Ni}$ alloy coating on the surface of the deposit density, and the adhesion strength of the matrix is good, not easy to fall off.

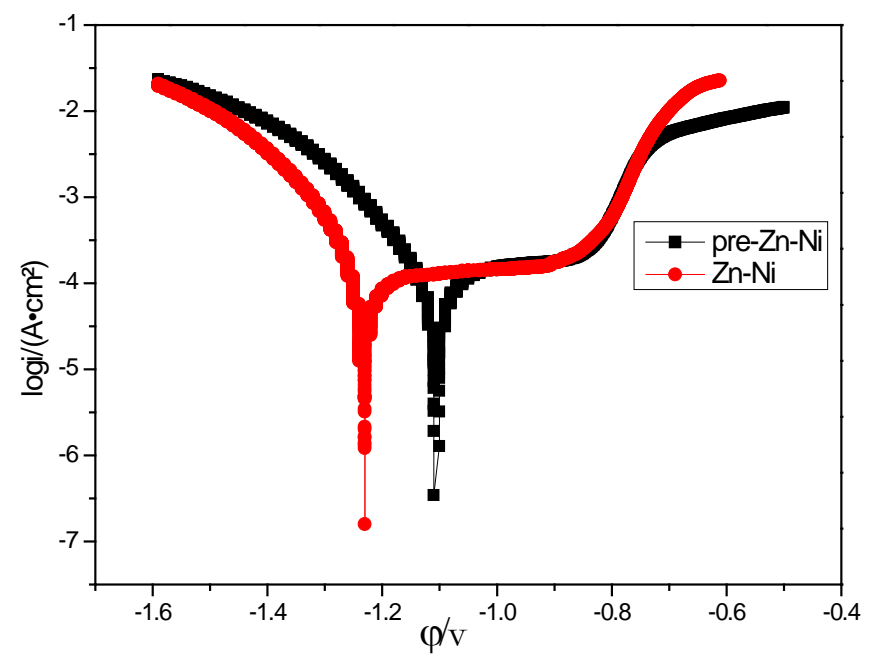

Figure 4 Potentiodynamic polarization curves of different coatings in $5 \mathrm{wt}$. \% $\mathrm{NaCl}$ solution.
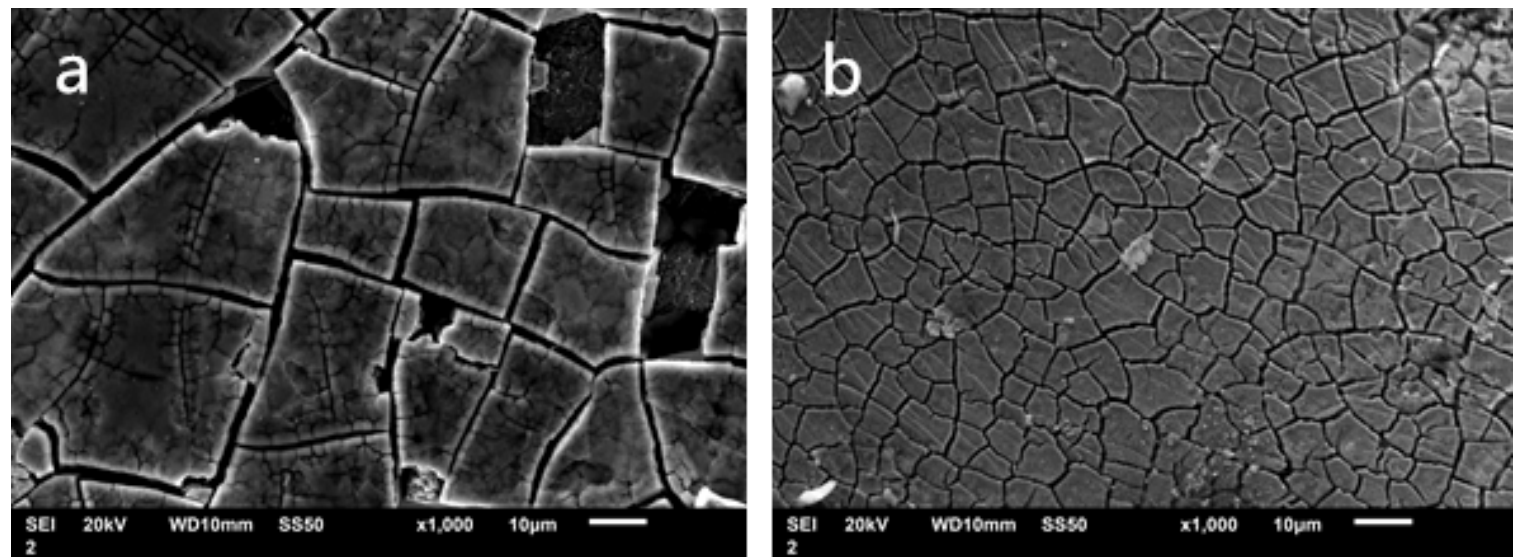

Figure 5 The SEM image of two samples in the $5 \% \mathrm{NaCl}$ solution for electrochemical corrosion (a) direct electrodeposition of Zn-Ni alloy coating, (b) after nickel pre-plating electrodeposition of Zn-Ni alloy coating.

\section{Conclusions}

(1) The combination of nickel and iron matrix can be formed good makes Zn-Ni alloy plating deposit more uniform, more refined surface organization, and successfully improves the $\mathrm{Zn}-\mathrm{Ni} / 304$ of stainless steel composite membrane adhesive strength.

(2) In $5 \% \mathrm{NaCl}$ solution, the corrosion potential of $\mathrm{Zn}-\mathrm{Ni}$ alloy coating after nickel pre-plating relative to the potential of direct plating $\mathrm{Zn}-\mathrm{Ni}$ alloy coating moves $127 \mathrm{mV}$, the corrosion current density is 0.812 times of $\mathrm{Zn}-\mathrm{Ni}$ alloy coating.

(3) Compared with the direct plating $\mathrm{Zn}-\mathrm{Ni}$ alloy coating, the corrosion resistant performance of the nickel pre-plating Zn-Ni alloy coating is better. The nickel pre-plating Zn-Ni alloy coating has the advantages of high corrosion potential, low corrosion current density, slow corrosion rate and so on, and simple preparation process. So it will make a greater contribution in the field of automated plating lines of the stainless steel workpiece. 


\section{Acknowledgement}

This research was supported by the National Nature Science Foundation of China (No. 51271153).We thank Chongqing LIDAO S\&T Co., Ltd and Southwest University for a variety of experimental tests .

\section{References}

[1] J. Y. Zhang: 'Study and Protection on Corrosion between the Crystal of 304 Austenitic Stainless Steel’, Equipment Manufactring Technology, 2012, 02,154-156.

[2] L. Cao, Z. Z. Zuo, et al.: 'Research Status and Prospect of Zn-Ni Alloy Electroplating', 4th edn, Vol. 43, 33-37; 2010, Materials Protection.

[3] J. J. Hu: 'Electroplating nickel technology for Stainless steel fine wire', PhD thesis, Northeastern University, Liaoning, China, 2008, 8-45.

[4] B. S. Zhang and W. Y. Jiao: 'A Brief Discussion on pretreatment for Stainless Steel Plating', Electroplating \& Pollution Control, 2014, 06, 45-46.

[5] X. Q. Ou-Yang and L. Y. Zhou: 'Research Status of Electroplated Nickel based Alloy Coating', 7th edn, Vol. 36, 20-24; 2014, Plating and Finishing.

[6] J. Yu: 'Fabrication and research about the mechanical and corrosion-resistance properties of electrodeposited nanocrystalline nickel’, PhD thesis, Jilin University, Jilin, China, 2007, 15-32.

[7] K. L. Huang, Y. Y. Tang and L. Q. Nong.: 'Experiment study of the phase analysis on the Ni-Zn alloys', 4th edn, Vol. 30, 8-11; 2010, Physics Experimentation.

[8] Y. M. Zhang, J. D. Pan, and Z. H. Li, Z. Xu.: 'Advances in the Research of Intermedate Layers of Steel Substrates for Diamond Films’, 9th edn, Vol. 20, 86-97; 2006, Materials Review.

[9] R. B. Chu, S. W. Dai and L. B. Yang.: 'Nano-nickel Pre-plating Process for Stainless Steel', 10th edn, Vol. 35, 14-16; 2013, Plating and Finishing.

[10] K. Zheng, Y. J. Han, et al.:'Comparison of the anti-corrosion performance between electrodepositing $\gamma$-shape Zn-Ni alloy film and Zn film’, 1st edn, Vol. 35, 71-74; 2014, China Surface Engineering.

[11] B. Kavitha, P. Santhosh and M. Renukadevi.:'Role of organic additives on zinc plating', Surface\& Coatings Technology, 2006, 201, 3438 -3442. 